IJAMSR 3 (1) www.ijamsr.com CrossRef: https://doi.org/10.31426/ijamsr.2020.3.1.3012

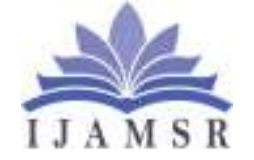

International Journal of Advanced Multidisciplinary Scientific Research (IJAMSR) ISSN:2581-4281

\title{
DESIGN OF LOCAL THRESHOLDING BASED RETINAL VESSEL SEPARATION
}

\author{
Mohammad Sami' ${ }^{1}$ Dr. Avinash Gour ${ }^{2}$ \\ ${ }^{1}$ Research Scholar, Dept. of Electronics and Communication Engineering, Sri Satya Sai University of \\ Technology \& Medical Sciences, Sehore, Bhopal-Indore Road, Madhya Pradesh, India. \\ ${ }^{2}$ Research Guide, Dept. of Electronics and Communication Engineering, Sri Satya Sai University of \\ Technology \& Medical Sciences, Sehore, Bhopal Indore Road, Madhya Pradesh, India \\ Email: samisbit@gmail.com
}

\section{Keywords: \\ Retinal image; \\ Optic nerves detection; \\ Gradient descent method; Signed Pressure Force function.}

\begin{abstract}
A B S T RA C T
Limitation and division are significant errand in clinical picture examination. As we probably am aware identification of optic nerves is additionally a significant issue in mechanized retinal picture investigation framework. Picture division of clinical picture is exceptionally unpredictable and vital advance, in this arrangement division of retinal picture is more mind boggling in examination of others. For the retinal picture division, we use angle drop technique. Late exploration is centre around better exactness rate. This paper gives a superior over all the discovery procedure toward reasonable division of optic nerves utilizing inclination drop technique (GDM). For instatement of nearby form, we utilize Signed weight power work (SPF) which is district based dynamic shape model.
\end{abstract}

Citation: Mohammad Sami, Dr. Avinash Gour (2020). Design Of Local Thresholding Based Retinal Vessel Separation. International Journal of Advanced Multidisciplinary Scientific Research (IJAMSR) ISSN:2581-4281, 3(1), January 2020, pp 15 - 22 
IJAMSR 3 (1) www.ijamsr.com CrossRef: https://doi.org/10.31426/ijamsr.2020.3.1.3012

\section{International Journal of} Advanced Multidisciplinary Scientific Research (IJAMSR) ISSN:2581-4281

\section{Introduction}

The optic nerve is one of the most significant organs in the human retina. The focal retinal supply routes are going from the focal vein of the retina through the optic nerve, by the external layers of the retina with the blood. The optic nerve additionally fills in as middle for the progression of data between the eye and the cerebrum. The optic nerve can be analyzed in a perception of retinal pictures. The Retinal picture is an inside surface of the eye, counting the retina, optic circle and macula and so on Retinal imaging is a typical clinical system used to record a perception of the retina. The picture can be utilized for conclusion, therapy, assessment and upkeep of clinical history.

Location of optical nerves is a significant advance in the improvement of frameworks for computerized analysis of different genuine eye illnesses. It is planned a significant in slope plummet numerous pre-preparing calculations use consequently recognize different properties of the retinal picture. The moderately consistent separation between the external breadth and the fovea can be utilized to encourage the assessment of the situation of the optical plate. Models of the back aspect of the eye sickness are fluctuated and as a rule require ID by a certified eye specialist as clinical human spectator. The utilization of advanced retinal imaging in ophthalmology furnishes us with digitized information, which could be utilized regarding PC controlled location of the infection. To be sure, numerous specialists use modernized picture examination of the eye, under the direction of a human onlooker [1].

The OD areas eliminated prior to distinguishing retinal exudates, which are utilized to evaluate macular Edema dangers and quality. The components of the optical circle can likewise be utilized to measure properties because of unusual glaucoma. Glaucoma is distinguished by identifying changes fit as a fiddle, shading or profundity, delivered in the optic circle. In this manner, the division and examination can be utilized to naturally distinguish the characteristic of glaucoma. OD identification isn't a simple thing. Macular district, they are a significant reason for treatable vision misfortune in the non-proliferative types of diabetic retinopathy. It is helpful to have made a mechanized strategy for identifying retinal exudates in computerized pictures of screening programs for diabetic retinopathy [2]. 
IJAMSR 3 (1) www.ijamsr.com CrossRef: https://doi.org/10.31426/ijamsr.2020.3.1.3012

\section{International Journal of Advanced Multidisciplinary Scientific Research (IJAMSR) ISSN:2581-4281}

Picture division is a cycle for the partition of the picture pixels dependent on at least one chose picture, and for this situation the capacity of the chose division, the shading properties. The point is the pixels of various tones in various locales and a similar time a gathering of pixels that are spatially associated and have a comparative tone to be isolated in a similar area. Picture division has consistently been major issue and complex undertaking in the field of picture handling and PC vision. He will probably change, to change the portrayal of a picture into something that is more significant and simpler to dissect.

The optical circle is situated in the PCA based model. The area is utilized for layout coordinating. Layout is intended to embrace diverse picture goals. The pixel with the base separation in the applicant areas at all scales is situated as the focal point of the optic plate. PCA is a numerical system that utilizes symmetrical change to various perceptions can be utilized with a lot of variable qualities corresponded straightly connected factors called head parts convert. The quantity of head parts is not exactly or equivalent to the quantity of the first segments.
The shading retinal pictures are utilized to screen eye illness by ophthalmologists. Build up the foundation picture consequently eye investigation and analytic framework is to encourage a definitive objective of our examination to the clinical conclusion. Extraction of ordinary and strange elements of the eye, in the shading picture and the foundation is essentially valuable for understanding the programmed retinal pictures. Typical properties retinal pictures incorporate optical circle, fovea and veins. Exudates and anomalous draining are the principle highlights of diabetic retinopathy are the main source of visual impairment in the number of inhabitants in working age [3].

Dynamic shape model has demonstrated to be a viable system for picture division. The fundamental thought of the dynamic form model is to begin with a bend around the item to be distinguished, and the bend moves and stops within the genuine typical limit of the article based on a minimization of the energy utilization model. Level set strategy depends on the model-based and the dynamic forms intended to treat the division of the deformable structures. Commonly utilize the conventional 
IJAMSR 3 (1) www.ijamsr.com CrossRef: https://doi.org/10.31426/ijamsr.2020.3.1.3012

dynamic form model wedges to the limit of a displayed object. Nonetheless, the level set strategy is to utilize a deformable front bend to inexact the limit of an item. Of the level set, the bend goes through the beginning, called a smooth, for the most part characterize the capacity of level change implies appeared. Dislodging bends should be possible by changing the level set capacities as opposed to bouncing bends. In this way, the level-set strategies have intriguing flexible conduct and can successfully deal with the topological changes is likewise a favorable position contrasted with traditional dynamic form model [4].

\section{RELEATED WORK}

The optic circle limitation and division are significant undertakings in a mechanized retinal picture examination. The framework regularly denounced edge recognition calculations for general use to disappointment Segment of the optical plate by fluffy limits, conflicting Image contrast or missing highlights. Jihene Malek Presents a technique to naturally find and limit distinguish of the optic plate [1] which contains two autonomous systems ie area philosophy and limit division approach and accomplished 89\% right location and $95.05 \%$ normal precision in restricting the optic circle limit. M. Foracchia was introduced a mathematical parametric model [8] dependent on vascular structure, are subject to the accessibility of a decent segment of this structure in the picture, and autonomous of the real perceivability (or even presence) of the OD. The information tests of vessel centerline focuses and relating vessel bearings, given by any vessel recognizable proof methodology, model boundaries. The accessibility of a vessel extraction methodology is an important essential for our procedure. The OD position was accurately distinguished in 79 out of 81 pictures (98\%), even in rather troublesome obsessive circumstances. In any case, the strikingly great outcomes we got utilizing the information given by either strategy utilized in this work, which were algorithmically unique and freely created, propose that this is certifiably not a basic issue.

Huiqi Li depicted a methodology [5] which is consequently separate the principle highlights and powerfully in shading Retinal pictures dependent on approach like optic circle limitation and optic plate shape recognition by two unique strategies. The confinement is give 
IJAMSR 3 (1) www.ijamsr.com CrossRef: https://doi.org/10.31426/ijamsr.2020.3.1.3012

\section{International Journal of \\ I J A M S R \\ Advanced Multidisciplinary Scientific Research (IJAMSR) ISSN:2581-4281}

a superior depiction of the component in Retinal pictures or inside surface territory of eye. The achievement rates accomplished are 99\%, 94\%, and $100 \%$ for plate confinement, circle limit location, and fovea restriction individually. The affectability and explicitness for exudates discovery are $100 \%$ and $71 \%$. The achievement of the proposed calculations can be credited to the use of the model-based strategies.

Adam Hoover [7] depicted a mechanized strategy to find the optic nerve in pictures of the visual fundus. They introduced another technique to consequently find the optic nerve in a retinal picture. These procedures utilized the assembly of the vein network as the essential component for location, related to the splendor of the nerve as optional properties. Above techniques effectively identify the nerve in $89 \%$ of the cases, and in $100 \%$ of the sound cases. For finding the assembly of the vein network depends on calculation called fluffy union. Dissimilar to least-squares and Hough-spacebased arrangements, fluffy union uses the endpoints of the direct shapes if there should arise an occurrence of vein fragment to help discover the arrangement. Recognizing the crossing point of various lines (an assembly) is a key mathematical issue, with applications going from cosmology to designing, for example, model fitting and expectation.

Aliaa Abdel-Haleim Abdel-Razik Youssif are presents a technique [9] to naturally identify the situation of the OD in advanced Retinal pictures. This incorporates the inside surface of the eye, macula, retina and so on The OD discovery calculation depends on coordinating the normal directional example of the retinal veins. A straightforward coordinated channel is generally used to coordinate the bearing of the vessels at the OD region. The retinal vessels are divided utilizing a basic and standard 2-D Gaussian coordinated channel. The sectioned vessels are then diminished, and sifted utilizing neighborhood power, to speak to at long last the OD-focus up-and-comers. The contrast between the proposed coordinated channel resized into four unique sizes, and the vessels' bearings at the encompassing zone of every one of the ODfocus The OD place was distinguished accurately in 80 out of the 81 pictures $(98.77 \%)$. Also, the OD-focus was identified accurately in the entirety of the 40 pictures $(100 \%)$ utilizing the freely accessible DRIVE dataset. 
IJAMSR 3 (1) www.ijamsr.com CrossRef: https://doi.org/10.31426/ijamsr.2020.3.1.3012

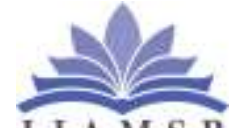

\section{International Journal of Advanced Multidisciplinary Scientific Research (IJAMSR) ISSN:2581-4281}

\section{METHODOLOGY}

There are various methodologies which are used earlier for optic disc boundary detection. A principal component analysis (PCA)-based model was chosen to serve this purpose. Principal component analysis (PCA) is a mathematical method using orthogonal transformation, a set of correlated variables observed in a group of values of uncorrelated variables called substantially linear transform components. The number of principal components is less than or equal to the number of the original variables. Then the model approach PCA (Principal Component Analysis) is applied to the candidate regions to give the final placement of the optical disk. First, a simple method for grading the intensity image to the candidate regions where the plate appears and then PCA is applied only to the candidate regions to locate the papilla can find. PCA is a powerful tool in the recognition of identical shape shaped shapes CPA-based approach consists of three steps. Figure. 1 presents the set of input retinal images where they Firstly, the eigenvectors of the training images are calculated. Then, a new image of the retinal is projected specified by the eigenvectors. Finally, the distance between the image of the fundus and its projection is calculated.
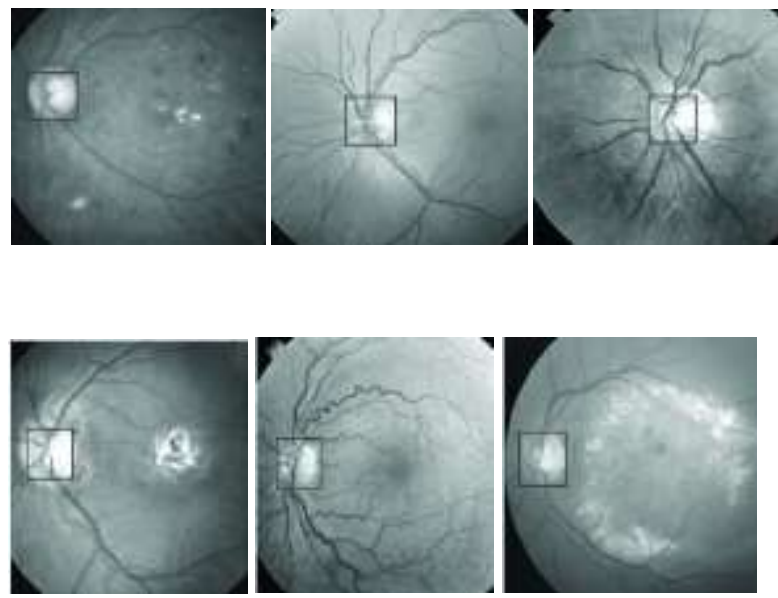

Fig 1: Input Retinal Image

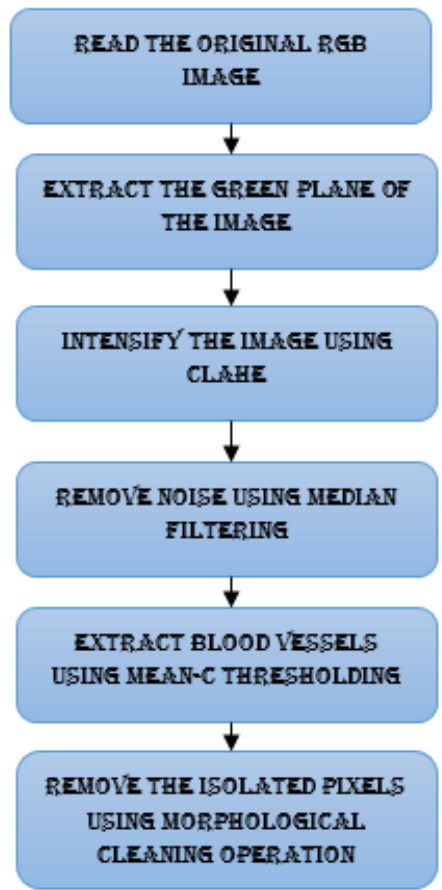

Figure 2: Flow chart of the proposed model 
IJAMSR 3 (1) www.ijamsr.com CrossRef: https://doi.org/10.31426/ijamsr.2020.3.1.3012

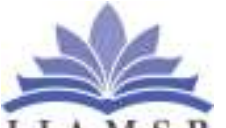

\section{International Journal of}

Advanced Multidisciplinary Scientific Research (IJAMSR) ISSN:2581-4281

\section{Results}

MATLAB (grid lab) is an elite language for specialized figuring. Math and calculation, Algorithm advancement, Data procurement, Data examination, investigation, representation, and so on, only procedure appropriate to this framework is,

\section{i) Threshold Method}
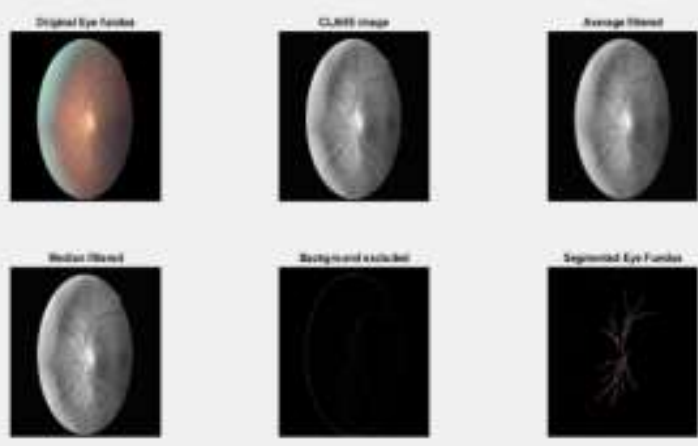

Figure 3: Output image

\section{Conclusion}

Considering the consequences of the runtime and the order exactness of the SLIC and Dbscan of eye fundus pictures by Messidor information base. The point was to analyze nature of the subsequent division utilizing a progression of insights: Runtime is the time division takes to perform contrasted with the quantity of superpixels. More superpixels will make it conceivable individualizing more injuries, however then again will set aside more effort to run. This runtime is gone up against with the portion of wounds individualized by division, when contrasted with the most elevated detail announced (15000 superpixels). At long last, we likewise measure characterization exactness, to contrast order of Slic yield and grouping of Slic+DBScan. Sectioned districts from 100 pictures were alluded to as exudates, microaneurysm, draining or ordinary eye fundus, highlights were removed.

\section{References}

1) Jihene Malek, Mariem Ben Abdallah, Asma Mansour, Rached Tourki, "Automated Optic Disc Detection in Retinal Images by Applying Region-based Active Aontour Model in a Variational Level Set Formulation”, in proc. IEEE, 2012.

2) A. Osareh, M. Mirmehdi, B. Thomas, and R. Markham, Automated identification of diabetic retinal exudates in digital colour images, $\mathrm{Br}$. J. Ophthalmol., vol. 87, 2003.

3) C. Sinthanayothin, J. F. Boyce, H. L. Cook, and $T$ Williamson, Automated localization of the optic disc, fovea, and retinal blood vessels from digital colour Retinal images, $\mathrm{Br}$. J. Ophthalmol., vol. 83, 1999.

4) Xiao-Feng Wang, De-ShuangHuanga, HuanXu, "An efficient local Chan-Vese model for image segmentation”, in proc. Elsevier, 2009. 
IJAMSR 3 (1) www.ijamsr.com CrossRef: https://doi.org/10.31426/ijamsr.2020.3.1.3012

5) H. Li and O. Chutatape, A model-based approach for automated feature extraction in Retinal images, in Proc. 9th IEEE Int. Conf. Comput. Vis. (ICCV03), 2003, vol. 1.

6) A. Hoover and M. Goldbaum, Fuzzy convergence, in Proc. IEEE, Comp. Soc. Conf. Comput. Vis. Pattern Recognit, Santa Barbara, CA, 1998.

7) A. Hoover and M. Goldbaum, Locating the optic nerve in a retinal image using the fuzzy convergence of the blood vessels, IEEE Trans. Med. Imag., vol. 22, no. 8, Aug. 2003.

8) M. Foracchia, E. Grisan, and A. Ruggeri, Detection of optic disc in retinal images by means of a geometrical model of vessel structure,IEEE Trans. Med. Imag., vol. 23, no. 10, Oct. 2004.

9) A. R. Youssif, A. Z. Ghalwash, and A. R. Ghoneim, Optic disc detection from normalized digital Retinal images by means of a vessels direction matched filter, IEEE Trans. Med. Imag., vol. 27, 2008.

10) P. C. Siddalingaswamy, K. G. Prabhu, Automatic localization and boundary detection of optic disc using implicit active contours, International Journal of Compuzter Applications, Vol. 1, pp. 1-5, 2010.

11) A. Aquino, M. E. Gegndez-Arias, and D. Marn, Automated optic disc detection in retinal images of patients with diabetic retinopathy and risk of macularedema, International Journal of Biological and Life Sciences 8:2, pp. 87-92, 2012.
12) J Xua" O Chutatapeb, E Sungc, C Zhengd, P. C. T Kuand,Optic disk feature extraction via modified deformable model technique for glaucoma analysis, Pattern Recognition, Vol. 40, 2007.

13) A. Osareh, M. Mirmehdi, B. Thomas, and R. Markham, Comparison of colour spaces for optic disc localisation in retinal images, in Proc. 16thInt. Conf. Pattern Recognit., 2002, pp. 743746.

14) Chunming Li, Chiu-Yen Kao, John C. Gore, and Zhaohua Ding, minimization of regionscalable fitting energy for image segmentation, ieee transactions on image processing, vol. 17, no. 10, october 2008.

15) H. Li, O. Chutatape, Automatic location of optic disk in retinal images, in: Proceings of the International Conference on Image Processing, vol. 2, October 2001.

16) Thord Andersson, Gunnar Lathen, Reiner Lenz, and Magnus Borga. A fast optimization method for level set segmentation. In Proceedings of the 16:th Scandinavian Conference on Image Analysis (SCIA), volume 5575 of Lecture Notes in Computer Science, Oslo, Norway, June 2009, Springer. 